\title{
Limites e Possibilidades do Planejamento Estadual Reflexões a partir da Experiência da Guanabara
}

\author{
Angela Moulin Penalva Santos
}

Este artigo discute os limites e as possibilidades do planejamento, considerado como instrumento de formulaçāo de polfticas. As reflexōes estāo referidas à cidade do Rio de Janeiro que, durante os anos 60 , sofreu uma verdadeira reforma urbana, derivada do impacto da realização de uma série de investimentos públicos sobre a sua estrutura urbanlstica.

\section{Abstract}

This article examines the limits and possibilities of planning, considered as an instrument of formulation of policies. The reflections refer to the city of Rio de Janeiro which, during the 60 's, experienced a true urban reform, resulting from the impact of the implementation of a series of public investiments. "Planejamento e desenvolvimento - o Estado da Guanabara", apresentada em outubro de 1990. 


\section{Introdução}

A complexidade crescente do processo de desenvolvimento de uma sociedade urbano-industrial requer uma gestão urbana que não pode prescindir da atividade de planejamento. Esta, por sua vez, envolve mais etapas do que a elaboração de diagnósticos, ainda que muitas vezes se restrinja a esta etapa básica. A abrangência do planejamento pode ser setorial ou global. Neste último caso, torna necessária a coordenação entre os distintos setores para compatibilizar demandas de serviços de educação, saúde e lazer com outras relativas à melhoria da infra-estrutura urbanistica.

Este artigo procura refletir sobre os limites e as possibilidades do planejamento, considerado como instrumento de formulação de poltticas com vistas ao desenvolvimento local. As reflexões estão referidas à cidade do Rio de Janeiro que, durante os anos 60, sofreu uma verdadeira reforma urbana, derivada do impacto da realização de uma série de investimentos públicos sobre sua estrutura urbanistica.

A cidade do Rio de Janeiro foi durante cerca de 200 anos a capital do pals. Em 1960, quando Brasllia foi criada e transformada em novo Distrito Federal, o Rio passou a ter status polftico-administrativo de Estado da Guanabara. Foi somente em 1975, depois da fusão da Guanabara com o antigo Estado do Rio de Janeiro, que o Rio se transformou em municipio.

Essa particular situação polftico-administrativa fez com que o desenvolvimento da cidade guardasse estreita relação com o desenvolvimento do país em suas distintas etapas, dentro das quais o Rio se inseria de diferentes maneiras. Assim, por exemplo, quando o Rio foi Distrito Federal, a cidade se beneficiou com os investimentos na infra-estrutura urbanistica por sua condição de capital federal, como foi o caso dos perlodos referentes à chegada da famflia real portuguesa em 1808 e da Reforma Pereira Passos, na primeira década do séc. XX. (Abreu, 1986) Por outro lado, durante as décadas de $60 \mathrm{e}$ 70 , quando a economia brasileira cresceu a taxas significativas, a cidade ficou praticamente à margem dos investimentos federais, seja na sua infra-estrutura urbanlstica, seja na infra-estrutura produtiva.

A partir do momento, então, que o Rio de Janeiro deixou de ser a capital do pals, as administrações locais, Estado de Guanabara e Prefeitura do Rio de Janeiro, passaram a ter um papel mais ativo na formulação de politicas de desenvolvimento urbano e regional. Discutir a formulação de tais polfticas, considerando sua inserção no processo de planejamento, constitui o objetivo deste trabalho.

\section{A Cidade Capitalista}

A concentração no espaço do desenvolvimento industrial torna a cidade um importante agente produtivo, fazendo-a objeto de análise quanto ao papel que desempenha no processo de acumulação capitalista.

$\mathrm{Na}$ fase inicial do processo de industrializaçāo, os trabalhadores sobreviviam em precárias condiçōes em cidades que somente se definem enquanto tal por terem seu espaço ffsico mais densamente ocupado, mas que ainda estavam desprovidas de equipamentos de consumo coletivo. À medida em que se intensifica o processo de acumulação, as cidades passam a ter maior importância por concentrarem cada vez mais capital e força de trabalho. (Lipietz, 1979; Lojkine, 1981)

Esse padrão de desenvolvimento concentrado resulta em necessidades novas, já que não originadas de uma empresa ou de um trabalhador ou consumidor individualmente, mas de um conjunto de empresas e da população. Estas necessidades correspondem 
aos chamados "meios de consumo coletivos" ou "capital social básico" Os capitalistas individualmente necessitam, por exemplo, de uma rede de circulação viária, assim como os trabalhadores devem ter acesso aos serviços de educaçāo e saúde que os tornem aptos a desempenharem funçōes cada vez mais qualificadas no processo produtivo. (Castells, 1977)

$O$ atendimento destas novas necessidades demanda substanciais investimentos com longo período de rotação do capital e, muitas vezes, baixa rentabilidade. Estas circunstâncias explicam o fato de que muitos destes investimentos, apesar de terem sido realizados pela iniciativa privada, foram sendo progressivamente estatizados, como foram os casos das estradas de ferro e da geração de energia elétrica. No Brasil, em particular, a simultaneidade entre a urbanização da população e o crescimento industrial gerou a necessidade de o Estado prover as cidades de infra-estrutura necessária à transformação de uma sociedade rural e primário-exportadora em outra, de base urbano-industrial. (Oliveira, 1982)

A cidade torna-se o produto de um conjunto de investimentos, públicos e privados. A apropriação do espaço urbano, no entanto, dá-se de forma privada, isto é, ocorre a apropriação privada de externalidades que os investimentos públicos podem gerar. Trata-se aqui da contradição entre a produção social e a apropriação privada do bem "espaço urbano" (Marx, 1977; Lipietz, 1979) É preciso, pois, considerar que, subjacente à intervenção do poder público na estrutura urbana, está a possibilidade de que os grupos sociais mais organizados e de maior representação na sustentação polftica dos governos obtenham maiores ganhos resultantes daquela intervenção. (Harvey)

As novas formas de organização social sempre se refletem na estrutura das cidades que, através de obras públicas, modificam-na para que se adapte à evolução das forças produtivas. Analisar, assim, os investimentos públicos pode ser um bom indicador da intervenção estatal no espaço urbano. $E$ mais, analisar como o poder público justifica os investimentos que realiza constitui elemento fundamental para uma discussão acerca do papel que o planejamento tem desempenhado no processo de desenvolvimento.

\section{A Intervenção Estatal e Desenvolvimento Capitalista}

Desde o surgimento do capitalismo industrial, o papel que o poder público cumpre na organização social, polltica e econômica da sociedade capitalista vem se ampliando como decorrência das demandas do próprio processo de desenvolvimento capitalista.

Desde a Grande Depressão dos anos de 1870, assiste-se a uma crescente concentração do capital, passando o desenvolvimento capitalista do estágio concorrencial para o monopolista. Neste, a pequena firma deixa de ser a unidade produtora arquetipica para ceder lugar à grande empresa, multiplanta e multiproduto, com reflexos importantes na forma de incorporação do espaço ao seu processo de desenvolvimento. (Hobsbawn, 1979)

Este processo de concentração do capital determina a concentração também da força de trabalho e, portanto, a socialização objetiva de seu processo de reproduçāo. Estas são as bases estruturais, tanto da formaçāo das grandes metrópoles como da exigência de desenvolvimento dos meios de consumo coletivo.

Estes meios de consumo coletivo - educação, saúde, transportes, equipamentos de lazer - são requeridos tanto pelo capital quanto pela força de trabalho, para que se reproduzam adequadamente. Sua produção, no entanto, depara-se com a questão da baixa rentabilidade que estes investimentos apresentam, $\circ$ que acaba por justificar a 
ampliação da intervenção do Estado, que é chamado a suprir as necessidades de infra-estrutura.

Do ponto de vista do capital, são investimentos que, em grande medida, possibilitam elou estimulam o consumo privado. Este é o caso do transporte individual - automóvel - cuja viabilidade depende da construção de uma rede rodoviária. Da mesma forma, a expansão urbana, incorporando áreas distantes do centro, como é o caso da Barra da Tijuca, na cidade do Rio de Janeiro, depende da existência de uma poltica habitacional de acesso à propriedade, assim como da expansão das auto-estradas. (Castells, 1977) Isto significa que o mercado imobiliário, uma das principais órbitas de valorização do capital naquela cidade, depende da ação do Estado, proporcionando as bases do consumo coletivo, com o qual viabiliza o consumo privado de unidades residenciais.

Do ponto de vista das demandas dos trabalhadores, os equipamentos de consumo coletivo a cargo do Estado têm permitido que o aumento do custo de reprodução do trabalho se viabilize mais pela elevação do salário indireto, de custo socializado, do que pelo salário direto, a cargo do capital.

Nestes termos, o Estado é chamado a intervir tanto na produção como na distribuição e gestão dos meios coletivos de consumo e, conseqüentemente, na organização e funcionamento das cidades, as quais resultam da articulaçāo do conjunto destes meios (transporte, educação, saúde, habitação, equipamentos culturais, dentre outros).

Observa-se, assim, que a acumulação capitalista industrial envolve uma ação solidária por parte do Estado, que se vê compelido a expandir sua área de atuação e, desta forma, contribuir para o desenvolvimento do capitalismo. Essa intervenção estatal não é, contudo, aleatória. Ela deve ser planejada para que logre cumprir adequadamente o seu papel no processo de desenvolvimento econômico.

\section{O Planejamento no Brasil}

Foi sobretudo a partir da revolução soviética e das propostas keynesianas que se tornaram patentes as possibilidades de intervenção planejada pelo poder público. A partir da II Guerra intensificaram-se as discussões em torno do processo de desenvolvimento econômico. Houve uma crescente conscientização do fosso que separava as nações de capitalismo central e periférico, disseminando-se a noção de "subdesenvolvimento" Nestas circunstâncias, o planejamento emerge como um instrumento a ser utilizado pelo Estado na sua tentativa de superação do subdesenvolvimento.

Desde a Revolução de 1930 e a ascensão do capitalismo industrial que se vem discutindo no Brasil as perspectivas do planejamento. Essas discussōes estão inseridas num contexto de crescente intervenção do poder público na atividade econômica, com crescente centralização do poder pelo governo da União e desarticulação das políticas regionais autárquicas. (lanni, 1977)

Durante a década de 30, a grande depressão atingiu a, então, atividade mais dinâmica da economia brasileira, o complexo agroexportador cafeeiro, propiciando, por outro lado, a aceleração da industrialização por substituição de importações. A indústria, por sua vez, necessitava de mercados em expansão e de infra-estrutura produtiva. Esta última, caso ficasse inteiramente a cargo do capital privado, iria se somar ao próprio investimento produtivo, encarecendo-o muito e, assim, dificultando a sua expansão. $O$ Estado Desenvolvimentista no Brasil passa, então, a ampliar a dotaçāo daquela infraestrutura, no sentido de estimular o capital privado, além de, com o mesmo intuito, unificar o mercado nacional, permitindo melhor circulação de mercadorias. (Cardoso, 1980; lanni, 1977) Estas novas funções que o Estado incorpora torna a atividade de planejamento um imperativo. 
Durante as décadas de 30 e 40, tais atividades circunscreveram-se às tentativas de racionalizar os dispêndios públicos, considerando-se apenas setores de atividades econômicas. Ainda assim, sofreram ataques de grupos ideologicamente identificados com a "liberalização da economia" isto é, com a readaptação do Brasil àquela antiga divisāo internacional do trabalho, pela qual éramos exportadores de produtos primários e importávamos manufaturados.

No final da década e 40, a CEPAL apresentou sua proposta desenvolvimentista para a América Latina, considerando a industrializaçāo o instrumento por meio do qual a regiāo lograria atingir os niveis de bem-estar desfrutados pelas populaçōes dos países industrializados e, por isso, desenvolvidos. Segundo esta proposta, o Estado constituirse-ia no sujeito do processo de planejamento industrial. (Cardoso, 1980)

As propostas cepalinas serviram de justificativa ideológica para que o Estado assumisse as rédeas do processo de industrialização, através da elaboração do primeiro plano de desenvolvimento efetivamente implantado no Brasil, o Plano de Metas, do governo Juscelino Kubitsheck. A partir de então, o planejamento foi incorporado à polftica pública, com todas as administraçōes do governo federal apresentando um plano com o qual orientar, pelo menos, o perfodo de duração de cada gestão.

Assim, no inf́cio da década de 60, o planejamento já tinha se tornado um recorrente instrumento de formulação de polfticas. $O$ grande salto quantitativo e qualitativo que a economia brasileira tinha dado na década anterior, graças à ação do poder público, respaldava a sua adoção. Mas é importante observar que este planejamento não contemplava a possibilidade de reformas mais profundas na ordem poltica, social e econômica. $O$ planejamento aceito referia-se a uma atividade que permitiria a racionalização dos procedimentos que gerariam o desenvolvimento econômico.

\section{Planejamento Estadual: a Guanabara e o "Planejamento por Negociação"}

Um processo clássico de planejamento compreende as seguintes etapas: a) diagnóstico; b) objetivos; c) metas; d) estratégia; e) instrumentos; e f) controle. Dentre elas destaca-se o diagnóstico, como etapa crucial para que sendo identificados os problemas, o planejador possa estabelecer os objetivos a serem cumpridos e, através dos instrumentos mais adequados, tentar alcançá-los. Portanto, qualquer processo de planejamento deve iniciar-se com um minucioso levantamento de informaçōes, que permita a elaboração de um diagnóstico que reflita a situação da unidade espacial a qual o planejamento se refere.

Quanto aos objetivos e metas a serem estabelecidos pelo planejamento, devem ser apresentados considerando-se os reflexos de sua realização em relação ao espaço onde atuam. Isto é importante em função da possibilidade de que ocorram interesses divergentes entre unidades da mesma federação. Ao nivel dos estados esta possibilidade de divergência cria ainda maiores constrangimentos quanto à consecução do planejamento e a fundamental atividade de coordenaçāo entre os estados acaba por ser, quando muito, relegada ao segundo plano, já que o que predomina nas relaçōes entre eles é muito mais a competição do que a ação coordenada.

No que se refere aos instrumentos com os quais viabilizar a realização dos objetivos e metas do planejamento numa administração centralizada como no Brasil, a União acaba por deter o virtual monopólio sobre eles. Ficam a cargo do governo federal as decisōes relativas às polfticas fiscal, monetária, creditfcia e cambial. Os estados nāo têm controle sobre quaisquer daqueles possiveis instrumentos de polttica. Além disso, suas receitas orçamentárias reduziram-se consideravelmente após a reforma tributária de 1967. tornando-os cada vez mais dependentes das receitas de transferências, cuja 
aplicação já vem comprometida com algum programa especffico, consistindo no chamado "dinheiro carimbado" Somente após a Constituição de 1988 é que as instâncias estaduais e municipais recuperaram suas participaçōes na arrecadação fiscal.

Nestes termos, a realizaçāo de um processo de planejamento a nivel estadual ficava muito comprometida. Em função disso, uma grande parte da tentativa de planejar as economias estaduais não passava da realização de diagnósticos. Quanto à atuação sobre os problemas apontados pelo diagnóstico, ficavam quase sempre na dependência de negociação realizada entre os governos estadual e federal, que instrumentalizavam ou não os estados a lograrem seus objetivos e metas. (Boisier, 1972)

Dada esta situaçāo, o processo de planejamento estadual praticamente abandonou aquelas etapas de determinação dos objetivos e metas e o estabelecimento de estratégia e instrumentos para compreender as seguintes etapas: a) geração de informações; b) diagnóstico; c) recepção de papéis; d) negociação; e) controle e avaliação. Trata-se do chamado "planejamento por negociação". (Haddad, 1985) Neste tipo de planejamento, cabem basicamente duas funções aos governos estaduais: procurar ter acesso polftico ao governo federal e apresentar um profundo conhecimento da realidade econômica e social do Estado. O primeiro é fundamental não apenas para atrair para os estados investimentos da União, como também para receber recursos para financiar projetos; e, o segundo, para respaldar tecnicamente os setores e projetos a serem financiados, já tendo sido identificados os fundos disponfveis para determinados tipos de investimentos.

Este último aspecto é muito importante já que os Estados contam com uma série de fontes possiveis para financiar investimentos que entidades nacionais - BNDES, CEF ou internacionais - BID, Banco Mundial - procuram estimular. Cabe à burocracia estatal identificar todas as possibilidades de financiamentos de investimentos públicos, ciente de que tais recursos não têm aplicações alternativas. Estes recursos não poderão ser utilizados em outros projetos eventualmente mais prioritários. Portanto, não é o caso de criticar os governos estaduais pela "febre viária" característica dos anos $60 \mathrm{e}$ 70, já que, naquela época, os estados contavam com muitos recursos do Fundo Rodoviário Nacional com aplicaçōes vinculadas à infra-estrutura viária.

Após 1964, com a modernização conservadora das estruturas politicas, sociais e econômicas implementados pelo governo federal, o planejamento por negociação encontrou campo fértil para se desenvolver. Isto porque a suspensão das eleições para os governos estaduais, substituldas por indicaçōes dos colégios eleitorais estaduais, os executivos estaduais passaram a ter atuaçāo bem coordenada com o executivo federal. Naqueles estados onde a identificação entre as administraçōes federal e estadual fosse maior, os governos estaduais atuavam como poderoso "lobby" estimulando opções locacionais dos investimentos da União em seus estados, bem como conseguindo parcelas mais substanciais de transferências de capital para o financiamento de seus projetos. Este foi o caso de Minas Gerais que durante as décadas de 60 e 70 foi bastante beneficiado pelo governo federal.

Ao contrário de Minas Gerais, a Guanabara nāo se beneficiou com o "planejamento por negociaçāo". E isto por dois motivos principais. Todos os seus três governadores opunham-se politicamente ao governo federal, especialmente Carlos Lacerda. Além disso, com uma pequena área correspondente apenas ao antigo Distrito Federal, a Guanabara não contava com recursos que pudessem justificar muitas opções locacionais de investimentos da União.

Paralelamente a este fato, um outro elemento contribuiria para deixar a Cidade-Estado praticamente à margem dos investimentos federais. Trata-se da poltica de progressiva incorporação de outras áreas, além da costa do pals, à economia nacional. Esta polf́tica 
implicou a opção por desestimular a concentração da produçāo no eixo Rio-São Paulo. Desconsiderando as particularidades da economia da Guanabara em relação a São Paulo, tal polftica contribuiria ainda mais para a queda da participação do produto da Guanabara na economia do pals. Cabe destacar que, dentro deste contexto, foi ainda a economia de Minas Gerais uma das maiores beneficiárias desta polttica de desconcentraçāo que emerge num perlodo caracterizado por altas taxas de crescimento do produto nacional.

Assim, não contando com administração com bom trânsito no âmbito do governo federal, que pudesse sensibilizá-lo para sua problemática especffica, o planejamento econômico a nivel da União acabou por contribuir para o enfraquecimento da economia carioca dentro do cenário nacional, assim como propiciou, em grande medida, a decolagem da economia mineira. Isso pode ter sido resultado de uma incompreensão do governo federal em relaçāo aos problemas enfrentados pela Guanabara e pela incapacidade de suas administraçōes explicitarem tais problemas, de forma a lograr maior apoio por parte da União. Pode também ter sido o produto de um casamento de interesses econômicos com a legitimaçāo polticica requerida para a sustentaçāo do regime que havia transformado a federação numa "forma-aparência" apenas. Neste caso, não se justificaria beneficiar uma Cidade-Estado, na qual toda a sua população é urbana e vota maciçamente nos partidos poltticos de oposiçāo. (Penalva Santos, 1990)

Em 1975, o Governo Federal extinguiu a Guanabara e criou o novo Estado do Rio de Janeiro. A pretexto de consolidar a fusão, a União nomeou o governador do novo Estado. Esta nova situação deveria superar as dificuldades que a administração da cidade do Rio de Janeiro enfrentava num contexto de "planejamento por negociaçāo"

Cabe lembrar, além disso, que este perlodo coincide com aquele em que o planejamento alcançou o maior prestígio enquanto estratégia para formulaçāo de poltiticas públicas. Foi nesta época que ocorreu o seu maior grau de institucionalização. A própria fusão pôde ser considerada como parte da estratégia federal de promover o desenvolvimento espacialmente mais equilibrado. Ela foi sustentada pela Uniāo como uma medida necessária para estimular a difusão do crescimento a partir do núcleo da Região Metropolitana do Rio de Janeiro para o interior do Estado, agora situado dentro de uma mesma unidade da federaçāo. Para garantir o êxito deste crescimento descentralizado, - Governo Federal comprometeu-se com a localização no novo Estado, de uma série de investimentos públicos.

Isso, contudo, ocorreu num contexto em que a economia passava por uma reversão cfclica depois do "milagre brasileiro" o que acabou por comprometer a realização daqueles investimentos, além de outros, da iniciativa privada. A crise econômica gerou a necessidade de maior seletividade na realização dos investimentos públicos $\mathrm{e}$, dentro deste cenário, foi dada prioridade aos investimentos relacionados à produção de insumos básicos, localizados próximos a sua base de recursos naturais.

Nestes termos, quando o planejamento contou com maior nivel de institucionalização e quando havia a maior coordenaçāo possivel entre os executivos federal e estadual, o Rio não se beneficiou desta conjuntura polltico-administrativa favorável.

A partir de 1982 foram retomadas as eleições diretas para governadores e, em 1985, para prefeitos das capitais. A legitimação que o voto proporcionou aos executivos estadual e municipal levou a um questionamento em relação à centralização da arrecadação pela União e, portanto, do "planejamento por negociação". A Constituição de 1988 acabou por incorporar as demandas de Estados e Municípios estabelecendo novo critério de distribuição da receita tributária, de modo a instrumentalizar as administraçōes locais na realização de planejamentos estadual e municipal. 
Isso ocorre, entretanto, num contexto em que o Governo Federal tinha expandido significativamente suas atribuiçōes enquanto financiador de investimentos infra-estruturais. A descentralização da arrecadação, assim, só poderia coexistir com um setor público federal com situação fiscal equilibrada, caso ocorresse descentralização também nas atribuiçōes da União. A não realização da denominada "Operação Desmonte" acaba por agravar a crise fiscal, além da deterioração da infra-estrutura produtiva e social a cargo do setor público.

Nestas circunstâncias, o setor público perde a capacidade de realizar investimentos e de se colocar como sujeito da atividade de planejamento. A partir dal, torna-se necessário que seja refeito o concerto entre agentes econômicos e o Estado para que seja produzido um novo processo de planejamento.

Assim, o que entra em crise é aquele velho concerto que produzira o planejamento centralizado pelo Governo Federal. Porém, o planejamento continua sendo um imperativo para a viabilização da reprodução de uma sociedade urbano-industrial. Dentro deste novo contexto, os interesses locais emergem com maior importância, especialmente quando são melhor informados e mais bem organizados, como é o caso da população do Rio de Janeiro. Neste sentido, cabe esperar que o planejamento que emerja deste novo cenário envolva modificaçōes qualitativas na orientação dos investimentos implementados pelas administraçōes públicas.

\section{Planejamento e Reforma Urbana na Guanabara}

Durante os 15 anos (1960/1975) em que o Rio teve o status polfico-administrativo de Estado da Guanabara, o poder público estadual realizou inúmeros investimentos que implicaram numa grande intervenção no espaço urbano carioca. A verdadeira reforma urbana dal decorrente resultou de obras tais como a construçāo do Túnel Rebouças, Trevo dos Marinheiros, Avenida Radial Oeste, via expressa do Aterro do Flamengo, Elevado e Túnel do Joá e Túnel Dois Irmãos. Esses investimentos no transporte urbano permitiram uma significativa expansão da cidade, tendo sido incorporados à malha urbana a pouco habitada Zona Oeste e a Baixada de Jacarepaguá, localidades que, desde então, correspondem aos principais vetores de expansão do município.

Essa reforma urbana, no sentido haussmanniano, foi produto do planejamento e financiamento locais. (Penalva Santos, 1990) É preciso analisar como tal reforma se inseria no processo de planejamento estadual e como a Guanabara pôde arcar com o ônus do financiamento de tantas obras.

A economia carioca vinha se esvaziando desde que sua área de influência, o antigo Estado do Rio, estagnara com a migração da produção de café para São Paulo. Quando a indústria se torna o centro dinâmico da economia brasileira, este esvaziamento se acentua, relativamente ao dinamismo da economia paulista. Na segunda metade da década de 50, a crise da economia carioca torna-se uma questão intensamente debatida, já que o Rio perderia sua condição de Distrito Federal, com a transferência da capital para Brasflia.

Neste contexto, a implantaçāo do Estado da Guanabara foi percebida pelo executivo estadual como um momento propício à implementaçāo de uma estratégia de desenvolvimento que viabilizasse o crescimento da economia carioca, consolidando-a como segundo pólo econômico do pals. A reforma urbana, realizada durante os anos 60 , teria sido uma das faces desta estratégia que compreendia a criação de espaços adequados para a localização industrial, para expansão do uso residencial, além de oportunidades de aplicação rentável para os interesses imobiliários. 
A Guanabara, contudo, não contava com sistema de planejamento com o qual sustentar o conjunto de obras realizadas. Apresentava apenas uma série de entidades de planejamento setorial, sem que estas mantivessem um nivel adequado de coordenação. O planejamento efetuado praticamente circunscrevia-se à elaboração e execução do orçamento-programa. Para além do curto prazo, as atividades de planejamento no Estado resultaram na elaboraçāo de diagnósticos e de planos setoriais, como o Plano Viário.

Estas transformaçōes ocorridas na estrutura urbana do Rio foram realizadas durante os anos 60, quando a centralização exercida pelo Governo Federal em torno dos instrumentos de planejamento ainda não estava consolidada. Até a reforma tributária de 1967, os estados contavam com parcela maior da arrecadação fiscal, o que Ihes concedia maior grau de liberdade na implementação de planos de interesse regional.

Em função de sua condição de Cidade-Estado, a Guanabara contava ainda com a dupla arrecadação, isto é, aquela originária de sua condição de Estado e a outra, referente a sua condiçăo de município. Esta circunstância lhe permitiu financiar quase todo o seu plano de obras, com destaque para o plano viário do qual resultou a já referida "reforma urbana". Considerando-se, no entanto, que a dupla arrecadação já era privilégio do Rio quando ainda era Distrito Federal, considero-a como condição necessária, porém não suficiente para a execução da "reforma urbana". A condição suficiente foi a necessidade de adaptar a cidade às novas formas de organização social, decorrentes da mudança no padrão de desenvolvimento ocorrido na economia brasileira a partir dos anos 50. Portanto, ainda que o Governo Estadual não contasse com um sistema formal de planejamento a sustentar a sua intervenção na estrutura urbana, sua atuação foi de tal ordem que resultou numa total reorganização urbana.

No início dos anos 70, quando assume o governo da Guanabara o seu terceiro e último governador, Chagas Freitas, foi criado o sistema de planejamento estadual. Isso se dá, entretanto, num contexto de esvaziamento da capacidade dos estados sustentarem a execuçāo de planejamento que contemplasse a sua realidade regional. O planejamento estadual tornara-se uma extensão do planejamento federal, ainda que a nivel institucional ele tivesse evolufdo significativamente. Assim, o que se observou foi que a reforma urbana do Rio precedeu a institucionalização do sistema de planejamento estadual e este, por sua vez, não garantiu uma polftica de consolidação da economia estadual carioca.

\section{Considerações Finais}

Toda essa discussão sobre a evolução do planejamento indica o prestlgio que esta atividade alcançou: diante da maior complexidade dos problemas, é preciso que se planeje as intervençōes públicas que objetivem a superação de tais problemas. Mas existe uma questão que está subjacente à forma como se apresenta a necessidade de superação dos problemas: trata-se de considerar quais são os agentes econômicos ou atores sociais para os quais uma dada situação é considerada "problema". Pois bem, no âmbito desta discussão sobre o planejamento estadual na Guanabara, a situação-problema era a estrutura da cidade do Rio de Janeiro, incompativel com uma nova forma de organização social estabelecida após a mudança do padrão de acumulação na economia brasileira a partir de meados da década de 50 . Os agentes econômicos para os quais a estrutura urbana do Rio era problemática eram os empresários, que necessitavam de áreas adequadas para uso industrial; os interesses imobiliários que, com as obras públicas, contariam com a apropriação de rendas fundiárias urbanas que iam sendo produzidas; e, a nivel mais geral, a indústria automobilistica, já que as obras viárias adaptaram a cidade ao uso do automóvel. 
Com o intuito de superar os "problemas" da cidade, tais como os acima referidos, o poder público estadual implementou uma série de obras públicas, especialmente viárias, do que resultou uma verdadeira "reforma urbana". Como toda reforma urbana, esta também representou a superação de uma série de problemas, como os acima apontados, porém suscitou outros tantos. Dentre estes, cabe destacar a maior intensidade do processo de segregação na cidade, resultado da reestruturaçāo dos valores do solo urbano, beneficiando as áreas que foram contempladas com as obras públicas e contribuindo para expulsar dali a população, cuja renda não acompanhou a valorização fundiária ocorrida.

Esta reforma urbana não foi objeto de um planejamento global, mas resultou praticamente de um plano de obras viárias, elaboradas pela SURSAN (Superintendência de Urbanização e Saneamento), um plano setorial, no qual o assunto foi tratado em seus aspectos técnicos. O planejamento era, então, considerado enquanto técnica e, portanto, neutro do ponto de vista social. Disto decorria que ele era utilizado para legitimar a intervençāo estatal no espaço. Neste sentido, o recurso ao planejamento escamoteava os interesses que estavam envolvidos na reforma urbana e encobria ou, pelo menos, não tratava adequadamente os interesses que contrariava.

Isto não equivale negar a importância da atividade de planejamento. $\mathrm{Na}$ verdade, à medida em que se intensifica o processo de socialização da força de trabalho e do capital, decorrentes da transformaçāo de uma sociedade rural e agrícola em uma outra, urbano-industrial, o planejamento torna-se mais importante. Mas muito do que se discutiu acerca do planejamento, durante o perlodo de vigência da Guanabara, estava impregnado de forte conteúdo ideológico para justificar "cirurgias urbanas" que adaptassem a cidade ao uso do automóvel e atendessem necessidades de diversificação das opçōes de valorização do capital, a nivel da cidade.

Estas consideraçōes são reforçadas pela observação de que, durante os anos 60 , quando a Guanabara sofreu o que chamei "reforma urbana", não havia se constitufdo, ainda, um sistema formal de planejamento estadual. Neste perlodo, a atividade de planejamento praticamente se restringiu à realização de diagnósticos, programaçāo orçamentária e algum planejamento setorial. A falta de coordenaçăo entre as entidades que, de alguma forma, realizavam, então, as atividades de planejamento, permitiu que interesses corporativistas pudessem ser confundidos com os interesses da população representada pela administração estadual eleita.

À medida, porém, em que se implementa um sistema de planejamento estadual, os planos de governo apresentam um aspecto mais globalizante, procurando dar conta de todas as áreas nas quais o setor público intervém, tanto naqueles relativos à produção de infra-estrutura produtiva, como social. A elaboração de um plano global de governo impōe à administração pública a necessidade de, pelo menos, considerar os vários aspectos da realidade social e econômica da unidade administrativa ao qual ela está referida. Neste sentido, a adoçāo de um sistema de planejamento já constitui um avanço no que concerne às demandas sociais que um estado desenvolvimentista vai postergando o atendimento. Portanto, é perfeitamente justificável o esforço dos governos na implementação de seus sistemas de planejamento, a partir dos quais orientar seus dispêndios.

Cabe, no entanto, argumentar que o simples estabelecimento deste sistema não constitui garantia de que as metas nele contidas serão atingidas. É preciso que estas emanem da sociedade, como, por exemplo, ocorreu com as demandas relacionadas à expansão da malha viária e da rede de abastecimento de água da Guanabara. Além disso, é fundamental que o poder público disponha de instrumentos com os quais viabilizar a realização das metas. No caso dos dois primeiros governos eleitos da Guanabara, 
- Estado contava com recursos próprios, de modo a lhe permitir financiar um grande número de obras que expandiram e reestruturaram a cidade do Rio de Janeiro. No infcio dos anos 70, entretanto, a centralização politica e fiscal imposta pelo Governo Federal retira dos estados parte dos recursos tributários com os quais aqueles financiavam os seus investimentos. Assim, os estados perderam instrumentos que poderiam Ihes ter permitido realizar metas de um possivel planejamento que contemplasse os interesses regionais. Nestes termos, estreitaram-se as margens de liberdade com que contavam para elaborar seus planos estaduais, os quais acabaram por se tornar planos complementares ao planejamento federal.

Pode-se argumentar, então, que o planejamento é um instrumento fundamental para permitir que o processo de desenvolvimento se realize sem criar pontos de estrangulamento, que obstaculizem a acumulaçāo capitalista numa sociedade urbano-industrial. No entanto, num contexto de crise econômica torna-se necessário que se estabeleça um novo concerto entre Estado e Sociedade para que o planejamento possa ser elaborado a partir de um novo quadro institucional que amplie suas possibilidades de lograr êxito.

Cabe acrescentar, ainda, que neste "novo concerto", o Estado certamente deixará de ser o sujeito de um planejamento indicativo característico do Estado Desenvolvimentista, tal como proposto pela CEPAL, dentro do contexto de subdesenvolvimento da América Latina dos anos 40 e 50 . Deverão ser redefinidos os papéis, tanto do Estado quanto dos demais agentes sociais e econômicos, para que o planejamento possa cumprir seus propósitos, sem, agora, as mistificaçōes que o cercavam e que escamoteavam os agentes que o requeriam e que dele se beneficiavam.

\section{Referências Bibliográficas}

ABREU, Maurfcio. Evolução Urbana do Rio de Janeiro. Jorge Zahar Editor, Rio de Janeiro, 1986.

BOISIER, S.; SILVA, A. T. H.; LODDER, C. Analisis del Sistema de Planeamiento Estadual en Brasil. Convênio CEPALIPEA, 1979, mimeo.

CARDOSO, Fernando Henrique. As ldéiase seu Lugar. Vozes, Petrópolis, 1980.

CASTELLS, Manuel. Crise do Estado, consumo coletivo e contradiçōes urbanas. In: POULANTZAS, N., org. O Estado em Crise. Graal Editores, Rio de Janeiro, 1977.

HADDAD, P. R. Dimensōes do Planejamento Estadual no Brasil: Análise de Experiências. IPEA/PNPE, 13, Rio de Janeiro, 1985.

HARVEY, David. Urbanismo y Desigualdad Social. Siglo XXI, Madrid, 1977.

HOBSBAWN, Eric. Da Revolução Industrial Inglesa ao Imperialismo. Forense, Rio de Janeiro, 1979.

IANNI, Octávio. Estado e Planejamento Económico no Brasil (1930-1970). Civilizaçāo Brasileira, Rio de Janeiro, 1977.

LIPIETZ, Alain. El Capitaly su Espacio. Siglo XXI Editores, México, 1979.

LOJKINE, Jean. O Estado Capitalista e a Questão Urbana. Livraria Martins Fontes, Rio de Janeiro, 1981.

MARX, Karl. O Capital. Civilização Brasileira, Rio de Janeiro, 1977.

OLIVEIRA, Francisco. O Estado e o Urbano no Brasil. In: Revista Espaço e Debates, 6. Cortez Editora, São Paulo, 1982.

PENALVA SANTOS, A. M. S. Planejamento e Desenvolvimento. O Estado da Guanabara. Sāo Paulo, 1990. Tese (Dout.) - FAUUSP. 